\title{
Neutralidad estatal, perfeccionismo indirecto y falibilismo moral*
}

\author{
MARIANO GARRETA LECLERCQ \\ Departamento de Filosofía \\ Universidad de Buenos Aires \\ Consejo Nacional de Investigaciones Científicas y Técnicas (CONICET) \\ mgarreta@filo.uba.ar
}

\begin{abstract}
Resumen: Mi propósito en el presente artículo es examinar dos argumentos consecuencialistas en favor de la tesis de la neutralidad estatal. Ambos argumentos, propuestos por Eduardo Rivera López y Will Kymlicka, combinan una concepción moral de los intereses racionales de las personas con una tesis epistemológica: el falibilismo moral. Sostendré que ambas propuestas fracasan como objeciones contra las políticas perfeccionistas en cuanto que padecen una inconsistencia conceptual inherente. O bien la tesis falibilista resulta prácticamente irrelevante, en cuanto que se predica de cualquier conjunto de creencias en las que podamos basar nuestras decisiones, lo que la inhabilita para formular objeciones contra las políticas perfeccionistas que no sean igualmente válidas para cualquier acción estatal, o bien conduce a una posición escéptica incompatible con los presupuestos de los que depende la consistencia interna del argumento.
\end{abstract}

Palabras clave: consecuencialismo, razones para la acción, escepticismo, cargas del juicio

\begin{abstract}
My aim in this paper is to analyze two consequentialist arguments in support of the liberal conception of state neutrality. Both arguments, proposed by Eduardo Rivera López and Will Kymlicka, combine a moral conception of rational interests of persons with an epistemological thesis: moral fallibilism. I shall argue that such arguments are unsuccessful as objections against perfectionist policies. My main thesis is that they involve a conceptual inconsistency. The fallibilist thesis is irrelevant in practice, because it affects any set of beliefs upon which we can base our decisions and actions, and thus, can support objections against all policies of the state, whether perfectionist or not. Unfortunately, the only way to avoid this conclusion involves a commitment with a skeptic position that undermines the argument's inner consistency.
\end{abstract}

Key words: consequentialism, reasons to act, skepticism, burdens of judgment

*Agradezco los comentarios críticos a versiones iniciales de este trabajo que me hicieron Osvaldo Guariglia, Graciela Vidiella, Julio Montero y, en particular, Eduardo Rivera López. Agradezco también las objeciones y sugerencias de los árbitros anónimos designados por la revista Diánoia.

Diánoia, volumen LI, número 56 (mayo 2006): pp. 33-65. 
Una de las ideas fundamentales que caracterizan a las teorías políticas liberales consiste en la afirmación de que el Estado debe ser neutral frente a las diversas concepciones del bien religiosas, filosóficas o morales a las que se adhieren los ciudadanos de las democracias contemporáneas. Dado que el término "neutralidad" puede dar lugar a ciertas confusiones, es conveniente introducir algunas precisiones. El requisito de neutralidad no exige que el Estado asegure a todos los ciudadanos iguales oportunidades de promover cualquier concepción del bien que suscriban libremente; ello se debe a que toda teoría de la justicia liberal pondrá límites a aquello que puede ser considerado una concepción permisible del bien. Los ciudadanos no podrán perseguir cualquier concepción del bien, sino sólo aquellas que respeten los principios de justicia. Tampoco debe confundirse la posición liberal con lo que John Rawls ha denominado "neutralidad de efectos": desde esta perspectiva, un Estado es neutral si y sólo si se abstiene de "toda actividad que aumente la probabilidad de que los individuos acepten una doctrina particular en detrimento de otras (a no ser que se tomen medidas que anulen, o compensen, los efectos de las políticas que así lo hagan)" (Rawls 1993, p. 193). El punto débil de la neutralidad de efectos es su evidente implausibilidad práctica. Como acertadamente sostiene Rawls, la vigencia de una concepción liberal de la justicia tendrá, en cualquier caso,

importantes efectos e influencias en la selección de las doctrinas comprensivas duraderas y capaces de ganar adeptos con el transcurso del tiempo; y es inútil tratar de compensar esos efectos e influencias, o incluso tratar de averiguar, con fines políticos, su alcance y profundidad. Debemos aceptar los hechos de la sociología política de sentido común. (Rawls 1993, p. 193)

Entendida en forma adecuada, la tesis de la neutralidad estipula, siguiendo a Rawls, que las instituciones que conforman "la estructura básica de la sociedad"1 no deben estar diseñadas con el propósito de favorecer concepciones religiosas, filosóficas o morales particulares ( $c f r$. Rawls 1993, p. 194). Tal como lo presenta Will Kymlicka, a la luz de este principio "el Estado no toma posición acerca de qué formas de vida son más valiosas y el deseo de prestar ayuda a una forma de vida por

${ }^{1} \mathrm{Al}$ hablar de "estructura básica", Rawls se refiere a "las instituciones políticas, sociales y económicas principales de una sociedad, así como el modo en que encajan entre sí en un sistema unificado de cooperación social de una generación a la siguiente" (Rawls 1993, p. 11).

Diánoia, vol. LI, no. 56 (mayo 2006). 
encima de otra es excluido como justificación de la acción del gobierno" (Kymlicka 1989b, pp. 883-884; las cursivas son mías). Esta última frase trae a escena una cuestión importante, la vinculación entre neutralidad y justificación. Peter De Marneffe ha profundizado en el análisis de las implicaciones de esta conexión conceptual; para él, la neutralidad liberal debe ser entendida como una "neutralidad de fundamentos" (neutrality of grounds). Según la definición que ofrece, un Estado satisface los requerimientos de dicha tesis cuando "los principios de justicia que regulan las instituciones sociales y políticas básicas" cumplen con el requisito de "ser justificables en términos de valores que toda persona razonable podría aceptar como la base de demandas morales con independencia de la particular concepción del bien que suscriba" (De Marneffe 1990, p. 253).

Ahora bien, un Estado viola la tesis de la neutralidad cuando se compromete con la afirmación del valor intrínseco de ciertos estilos de vida o defiende la superioridad de determinadas concepciones del bien, sean religiosas, morales o filosóficas. La consecuencia natural de estas posiciones es la aplicación de políticas perfeccionistas. Existen dos tipos principales de políticas perfeccionistas: las coercitivas y las no coercitivas. El primer caso admite, a su vez, dos variantes: a) el Estado puede obligar a la gente, mediante la amenaza de sanciones, a realizar una actividad o un conjunto de actividades que son consideradas valiosas; b) el Estado puede prohibir y sancionar actividades o estilos de vida tipificados como perniciosos. Sin embargo, como se adelantó, las políticas perfeccionistas no siempre involucran coacción directa. Muchos gobiernos se limitan, por ejemplo, a promover estilos de vida o creencias por medio de subsidios o incentivos económicos, sin aplicar penas o sanciones de ninguna clase. Un ejemplo común es la promoción de concepciones religiosas y morales por medio de apoyo financiero otorgado a Iglesias y escuelas confesionales. En tales casos no hay necesariamente coerción directa, al menos mientras nadie sea obligado o presionado a asistir a la Iglesia o las escuelas subvencionadas. ${ }^{2}$ Otras políticas no coercitivas frecuentes consisten en diversas estrategias de política cultural, educativa y publicitaria.

Existen diversas estrategias de fundamentación de la tesis de la neutralidad. Una línea de argumentación que ha mostrado tener gran influencia, y cuyo representante principal ha sido Rawls, apunta a demostrar que en las condiciones de pluralismo religioso, moral y filo-

\footnotetext{
${ }^{2}$ Debemos suponer, también, que hay suficiente libertad como para que existan instituciones alternativas (por ejemplo, escuelas laicas) a las promovidas por el gobierno.
} 
sófico que caracterizan a las democracias contemporáneas, las políticas perfeccionistas nunca podrán alcanzar el grado de consenso - no simplemente de consenso de hecho, sino de consenso basado en razones públicamente vinculantes- exigible para considerarlas legítimas. Dado este "hecho del pluralismo", 3 será necesario dejar de lado la apelación a concepciones del bien que resultarán inevitablemente controvertidas, para buscar bases de consenso y de razonamiento público que todos los afectados puedan reconocer como punto de partida adecuado para la justificación de las políticas estatales. ${ }^{4}$

Otra estrategia de defensa de la tesis de la neutralidad que ha tenido gran influencia posee, a diferencia de la precedente, un carácter eminentemente consecuencialista y podría ser caracterizada incluso como una forma de perfeccionismo indirecto (cfr. Hurka 1995, p. 38). En este caso, el punto de partida es la aceptación de algunas de las ideas básicas de los defensores del perfeccionismo. Se rechaza el escepticismo valorativo y se reconoce que es viable justificar, con base en buenas razones, la superioridad de ciertas concepciones del bien y estilos de vida. Por otra parte, se suscribe la idea de que una de las metas centrales de la acción del Estado consiste en promover en forma equitativa la buena vida - es decir, aumentar la probabilidad de que todas las personas puedan llevar adelante una buena vida-. La consecuencia natural de estas posiciones parece ser la convicción de que el gobierno debe intentar identificar la concepción o concepciones del bien correctas y proceder a brindarles un apoyo directo (a través de incentivos económicos, de la política educativa, de campañas orientadas a influir en la opinión pública, del uso de la ley penal, etc.). Los argumentos consecuencialistas en favor de la tesis de la neutralidad intentan, por el contrario, demostrar que esa estrategia es inadecuada o incluso contraproducente para satisfacer la meta perseguida. Aunque intenten promover el bie-

${ }^{3}$ Rawls ha sostenido el "hecho del pluralismo", es decir, la coexistencia en el seno de las sociedades democráticas de una amplia diversidad de doctrinas comprensivas religiosas, filosóficas y morales antagónicas, e incluso irreconciliables, constituye un rasgo estructural permanente de la cultura pública de dichas sociedades. Cfr. Rawls 1993, p. 36.

${ }^{4}$ Como afirma Rawls, "dado el hecho del pluralismo razonable, en la cultura pública de una sociedad democrática falta una base pública y compartida de justificación que pueda aplicarse a las doctrinas comprensivas" (Rawls 1993, pp. 60-61). En ausencia de esa base pública de justificación, "No hay, pues, razón alguna por la que cualquier ciudadano o asociación de ciudadanos debiera tener derecho a usar el poder político estatal para decidir cuestiones constitucionales esenciales o cuestiones de justicia básica según las directrices de la doctrina comprensiva propia de esa persona o de esa asociación" (Rawls 1993, p. 62).

Diánoia, vol. LI, no. 56 (mayo 2006). 
nestar de los ciudadanos, las políticas perfeccionistas tradicionales lo ponen en peligro. El mejor modo de promover en forma equitativa el bien de las personas sería renunciar a la aplicación directa de políticas perfeccionistas y, en consecuencia, suscribir la concepción liberal. El Estado neutral debería ser suscrito por los perfeccionistas porque constituye el mejor mecanismo, aunque indirecto, de satisfacer sus metas - por esa razón puede hablarse, precisamente, de "perfeccionismo indirecto"-

Hay una amplia variedad de argumentos en favor de la tesis de la neutralidad estatal que quedan inscritos en la estrategia consecuencialista. En este trabajo me restringiré a examinar y criticar dos variantes de lo que podríamos denominar el argumento "falibilista consecuencialista". El primero de ellos lo ha desarrollado Eduardo Rivera López (cfr. 1997, pp. 53-81), y el segundo, Will Kymlicka (cfr. 1989a, pp. 1113; 1990, pp. 203-204; 1995, pp. 81-82).

Antes de pasar a la reconstrucción y crítica de estas propuestas, quisiera hacer algunas aclaraciones preliminares. La primera se refiere al alcance de la discusión que desarrollaré y de las conclusiones que voy defender. Como adelanté, los argumentos falibilistas son sólo una de las alternativas disponibles dentro de la línea consecuencialista de defensa de la tesis de la neutralidad. Para ejemplificar la situación, basta con señalar que Kymlicka propone, además del que será examinado aquí, otros tres argumentos que no involucran la apelación a la tesis falibilista. ${ }^{5}$ Esta referencia se vincula con los límites de las conclusiones del presente trabajo. Si mis críticas a los argumentos falibilistas son correctas, ello no implica, obviamente, que la tesis de la neutralidad estatal no pueda ser justificada exitosamente por otros medios; por ejemplo, los restantes argumentos consecuencialistas desarrollados

\footnotetext{
${ }^{5}$ El primero de dichos argumentos critica las políticas perfeccionistas coercitivas con base en la tesis de que la vida de las personas no puede ser satisfactoria, a menos que sea guiada por creencias acerca de lo valioso suscritas por el sujeto (cfr. Kymlicka 1989a, p. 12, y 1990, p. 204). El segundo sostiene que la vigencia de un Estado neutral propiciaría la formación de una suerte de mercado libre de ideas en el que las concepciones y prácticas realmente valiosas o satisfactorias tenderían a predominar, ganando naturalmente más adeptos que las menos valiosas o insatisfactorias (cfr. Kymlicka 1990, p. 219). El tercer argumento se centra en la idea de que la aplicación de políticas perfeccionistas conducirá a "distorsionar [distort] la libre evaluación de formas de vida, hacer rígidas las formas de vida dominantes, cualesquiera sean sus méritos intrínsecos, y excluir inequitativamente los valores y aspiraciones de los grupos marginados y en desaventaja dentro de la sociedad" (Kymlicka 1989b, p. 900).
} 
por Kymlicka que no serán objeto de análisis en este trabajo, ${ }^{6} \mathrm{o}$ las conocidas e influyentes propuestas de Rawls, Nagel, Larmore o Barry. Lo que pretendo mostrar aquí es que una línea de defensa de la tesis de la neutralidad que parece, al menos a primera vista, muy plausible y que se encuentra profundamente arraigada en la tradición de pensamiento liberal posee profundas dificultades conceptuales. La segunda aclaración se refiere a lo que podríamos denominar los compromisos metaéticos de la discusión. Los interlocutores a los que se dirigen los argumentos que examinaremos no son los liberales, sino, por el contrario, aquellos que defienden la aplicación de políticas perfeccionistas. Hay un supuesto común en la mayoría de las posiciones perfeccionistas; se trata de la idea de que es posible discriminar, con base en buenas razones, entre creencias y prácticas susceptibles de ser calificadas como buenas/valiosas/dotadas de sentido, y creencias y prácticas que merecerían una caracterización opuesta. Normalmente, estos juicios son informados por doctrinas más amplias y abarcadoras de orden religioso, filosófico o moral que podríamos denominar, siguiendo a Rawls, "doctrinas comprensivas" (cfr. Rawls 1993, pp. 13 y 175). Muchas veces - pensemos en el caso de los adherentes a ciertas concepciones religiosas- el respaldo de los juicios acerca del valor o "disvalor", de la bondad o la perversidad de ciertos estilos de vida, depende directamente de la creencia del sujeto en la "verdad" de su doctrina comprensiva. Por supuesto, podría objetarse la pertinencia de aplicar el predicado "verdad" a posiciones que combinan, con frecuencia de un modo indisociable, tesis metafísicas y enunciados descriptivos, evaluativos y normativos. ${ }^{7}$ Podría rechazarse la pertinencia de otorgar valor cogniti-

\footnotetext{
${ }^{6}$ Debe quedar claro también que mi propósito aquí no es evaluar globalmente el éxito o fracaso de la defensa de la tesis de la neutralidad desarrollada por Kymlicka. Tal cosa supondría analizar los otros argumentos propuestos por el autor.

${ }^{7}$ Como se verá a lo largo del texto, Rivera López y Kymlicka aplican los términos "verdadero", "correcto" y "valioso" a doctrinas comprensivas y a concepciones del bien sin establecer distinción alguna entre aquéllos. Rivera López escribe, por ejemplo, "estamos preocupados por encontrar la verdad [...]; cualquier individuo racional está interesado en hallar o aproximarse a la doctrina moral o religiosa correcta" (Rivera López 1997, p. 66). Kymlicka habla de la posibilidad de cometer errores, de actuar con base en creencias falsas acerca del valor de nuestras actividades (cfr. Kymlicka, 1990, p. 203-205). Contrariamente a esta práctica, muchos filósofos reservan los predicados "verdadero/falso" para un uso teórico-cognitivo del lenguaje. Es frecuente distinguir también entre enunciados evaluativos y normativos, y utilizar el término "corrección" para hacer referencia al tipo específico de validez que correspondería a los enunciados de la última clase mencionada. Creo que el proceder de los autores, la omisión del empleo de estas distinciones,
}

Diánoia, vol. LI, no. 56 (mayo 2006). 
vo a las formas de realismo moral de corte metafísico involucradas en este tipo de posiciones. Jürgen Habermas sostiene, por ejemplo, que las visiones religiosas o metafísicas del mundo no pueden ser, en las condiciones contemporáneas, objetos de una creencia racional. ${ }^{8}$ La estrategia adoptada por los argumentos que examinaremos es diferente; la meta que persiguen es defender la superioridad de las políticas liberales, y en particular de un Estado neutral, sin cuestionar las creencias comprensivas y las concepciones del bien que suscriben los perfeccionistas. Ello implica no cuestionar la pretensión de que se dispone de una justificación apropiada para afirmar que la doctrina comprensiva que se suscribe o los juicios valorativos particulares derivados de ella son "verdaderos", "correctos" o, en algún sentido, "acertados" —ya sea que tales términos hagan referencia a la adecuación a un orden independiente de valores morales; a la adecuación a los valores compartidos, prácticas o tradiciones de una comunidad determinada; a la satisfacción de algún ideal de autenticidad, o a otras posiciones-.${ }^{9}$ Como veremos, lo que

apunta a evitar las controversias teóricas que pueden aparejar y a reflejar el uso del lenguaje de sentido común que puede atribuirse a la gran mayoría de sus interlocutores perfeccionistas en la arena política real. Por otra parte, la introducción de tales distinciones podría resultar directamente inaceptable, por ejemplo, para quienes sostienen ciertas formas de realismo moral (posición que, aunque sea en forma tácita, es muy frecuente entre los defensores de posiciones perfeccionistas). En mi discusión seguiré la práctica de los autores en el uso de los términos referidos (es decir, verdadero, correcto, valioso). Mi propósito en este trabajo es centralmente crítico y pretendo llevarlo adelante, no a través del cuestionamiento de los presupuestos básicos de los planteamientos discutidos, sino de su consistencia interna. Esta estrategia no implica que yo acepte o suscriba tales presupuestos.

${ }^{8}$ Cfr. Habermas 1992, pp. 24-37. Para él, a la luz de nuestra autocomprensión contemporánea, actuamos o pensamos sobre la base de razones que tomamos como válidas, no porque las consideremos garantizadas por el orden objetivo del mundo, sino porque suponemos que ellas podrían obtener el asentimiento de los otros en condiciones ideales apropiadas.

${ }^{9}$ En respuesta a un señalamiento de uno de los árbitros anónimos del presente trabajo quisiera dejar en claro que ni los argumentos que serán examinados, ni mi crítica a ellos dependen de o presuponen un compromiso con el realismo moral o con la equiparación entre el tipo de objetividad de la que da cuenta el lenguaje teórico-cognitivo y la que correspondería a las concepciones del bien. Los argumentos que examinaremos incorporan en sus premisas la idea de que podemos tanto cometer errores como corregirlos al afirmar una doctrina comprensiva o una concepción del bien, o al realizar un juicio particular acerca del valor de una práctica. Estos argumentos se comprometen, en síntesis, con la tesis de que es factible un progreso cognitivo racionalmente guiado en el campo referido. Por supuesto, dicha tesis puede ser conceptualizada y justificada de diversas formas. La apelación al realismo moral es una de las alternativas posibles. Bien interpretados, los argu- 
exigen los argumentos falibilistas es el rechazo del dogmatismo, es decir, de la pretensión de poseer la certeza plena de la verdad de la propia posición. Por el contrario, se exige que los agentes reconozcan que, por más confianza que tengan en la verdad de su creencias y en las razones por las cuales afirman dicha posición, deberán admitir que existe la posibilidad de que estén equivocados.

\section{II}

Como marco para construir su propuesta, Rivera López toma algunas de las categorías centrales desarrolladas por John Rawls en Political Liberalism, en particular, la distinción entre "razonabilidad" y "racionalidad", y el concepto de "cargas del juicio" (burdens of judgments). Las tres nociones mencionadas son atributos de la concepción política de persona propuesta por Rawls. Las personas, concebidas como ciudadanos libres e iguales, poseerían dos facultades morales básicas: un sentido de justicia, esto es, la capacidad de comprender, aplicar y actuar con arreglo a una concepción de la justicia, y la capacidad de poseer una concepción del bien, que implica la aptitud para formular, perseguir racionalmente y revisar una concepción del bien (cfr. Rawls 1993, pp. 30 y ss.). La primera facultad moral mencionada es denominada como la "facultad razonable"; la segunda, como la "facultad racional". ${ }^{10}$ Otro de los rasgos centrales del planteo rawlsiano consiste en la idea de que las personas razonables reconocen y son conscientes de las consecuencias de las "cargas del juicio" (cfr. Rawls 1993, pp. 54-58). Quisiera detenerme en esta última idea. Su introducción responde a la necesidad de

mentos de Rivera López y Kymlicka deberían ser capaces de ofrecer una defensa de la posición liberal compatible con diversas versiones de la tesis del progreso cognitivo — no sólo a la asociada al realismo moral—. El vocabulario que, según veremos, utilizan los autores (en particular, el de Rivera López, quien habla reiteradamente de "verdad moral", "concepción del bien verdadera", "aproximarse a la verdad", etc.) parece sugerir que se tiene en mente como interlocutor privilegiado a un realista moral, lo cual no resulta sorprendente, dado que, como ya se señaló, es una posición muy frecuente entre los defensores del perfeccionismo. Esta estrategia no implica un compromiso con el realismo moral, sino la pretensión de ofrecer un argumento convincente incluso para quienes suscriban esa posición (por ejemplo, los adherentes a diversas doctrinas comprensivas religiosas). Mis críticas ni siquiera supondrán una afirmación explícita de la corrección de la tesis del progreso cognitivo. Lo que intentaré demostrar es que 1) si se acepta, como hipótesis, una versión plausible de la tesis de progreso cognitivo, los argumentos no funcionan, y 2) que, dado que tal tesis, como se verá, es esencial para la economía conceptual de los argumentos, su eliminación también los desarticula.

${ }^{10}$ Ambas son componentes de la concepción de persona razonable.

Diánoia, vol. LI, no. 56 (mayo 2006). 
explicar el surgimiento, dentro de las sociedades democráticas, de una pluralidad irreductible de doctrinas comprensivas ${ }^{11}-\mathrm{y}$ concepciones del bien asociadas- religiosas, filosóficas y morales. Rawls afirma que "resulta poco realista -o peor, suscita mutuas sospechas y hostilidadsuponer que todas nuestras diferencias tienen sus raíces sólo en la ignorancia y en la perversidad, o en la rivalidad por el poder, el estatus o las ganancias económicas" (Rawls 1993, p. 58). En tal sentido, la función de las "cargas del juicio" es explicar el hecho del "desacuerdo razonable": la inexistencia de garantías de que las personas que usen en forma consciente y plena sus poderes o capacidades racionales arriben, aun tras el desarrollo de una discusión libre y abierta, a una misma conclusión. ${ }^{12}$

Rawls no pretende ofrecer una lista completa de las "cargas del juicio", sino poner a consideración algunas de las más obvias. Entre ellas estarían las siguientes: a) las evidencias relevantes, los datos o los hechos que deben ser analizados son conflictivos y complejos; por consiguiente, difíciles de establecer y evaluar; b) aun cuando estemos de acuerdo acerca del tipo de consideraciones que son relevantes para el caso en discusión, podemos disentir en relación con su peso e importancia y llegar a distintos juicios; c) nuestros conceptos morales y políticos son vagos y requieren juicio e interpretación (y juicio e interpretación de esos juicios e interpretaciones), lo que conduce a desacuerdos; d) el modo en que las personas evalúan y sopesan las evidencias y los valores está estructurado en cierta medida por su particular experiencia de vida (por ejemplo, por su posición social, su ocupación, su pertenencia étnica, etc.); e) la existencia de dilemas y conflictos morales; f) el hecho de que las sociedades deben realizar una selección de un número limitado de valores entre todos los que podrían ser realizados (dicha selección puede llevar a profundos conflictos).

Es importante señalar algunos contrastes entre el planteamiento de Rawls y la propuesta de Rivera López que examinaremos. Rawls consi-

${ }^{11}$ Una doctrina moral es comprensiva "cuando incluye concepciones sobre qué es de valor en la vida humana, e ideales sobre el carácter personal tanto como ideales de amistad, relaciones familiares y de asociación, y otros muchos elementos que conforman nuestra conducta y, finalmente, nuestra vida considerada globalmente". El autor sostiene, además, que las doctrinas comprensivas suelen ser también generales, es decir, que se aplican "a una amplia gama de temas [subjects], y en el límite, universalmente a todos los temas" (Rawls 1993, p. 13).

${ }^{12}$ Las "fuentes del desacuerdo razonable - las cargas del juicio- entre personas razonables son los muchos riesgos que entraña el ejercicio correcto y concienzudo de nuestros poderes de razón y juicio en el transcurso ordinario de la vida política" (Rawls 1993, pp. 56-57). 
dera que lo racional y lo razonable son facultades morales cooriginales, lo cual implica que no es posible derivar una de otra y, en particular, que no es posible derivar lo razonable de lo racional (cfr. Rawls 1993, pp. 51-52). Para el filósofo estadounidense, un rasgo básico de la razonabilidad, en cuanto que se predica de las personas, consiste en la disposición a

proponer principios y criterios en calidad de términos equitativos de cooperación y a aceptarlos de buena gana, siempre que se les asegure que los demás harán lo mismo. Las personas entienden que aceptar esas normas es razonable para todo el mundo y, en consecuencia, que son justificables ante todos, y están dispuestas a discutir los términos equitativos que otras propongan. (Rawls 1993, p. 49)

Estos rasgos de la idea de razonabilidad constituyen elementos esenciales de las nociones de cooperación equitativa y tolerancia democrática tal como son caracterizadas por Rawls. Asimismo, son esenciales en la justificación rawlsiana del compromiso de los ciudadanos con la búsqueda de una base pública de justificación de las políticas estatales que tome distancia de las controversias que giran en torno de doctrinas comprensivas religiosas, filosóficas y morales. A diferencia de Rawls, Rivera López considera que este último complejo de ideas (cooperación equitativa, tolerancia, etc.) puede ser derivado y justificado sin apelar a la referida noción de razonabilidad. Su tesis es que tal derivación es posible a partir de dos premisas más básicas que la noción de razonabilidad que se pretende fundamentar. ${ }^{13}$

La primera de tales premisas consiste en el concepto de lo racional tal como, según vimos, era definido por Rawls; es decir, como una facultad moral que consiste en la capacidad para plantearse fines y planes de vida y articular los medios para llevarlos adelante. ${ }^{14}$ La segunda

${ }^{13}$ Como el propio Rawls señala, existe una importante tradición dentro de la historia del pensamiento moral que ha creído que lo racional es más básico que lo razonable y que una derivación de dicho concepto a partir del primero ofrece las mejores posibilidades de alcanzar una justificación sólida (cfr. Rawls 1993, pp. 5152). A diferencia de Rawls, Rivera López se inscribe en la tradición referida. Aunque simpatizo con la posición de Rawls en este punto, no abriré juicio aquí acerca de las ventajas y debilidades de las dos posiciones relativas al carácter básico o derivado del concepto de lo razonable. Mi meta en esta sección del trabajo es más restringida: lo que pretendo es cuestionar la particular versión propuesta por Rivera López de la derivación de lo razonable a partir de lo racional.

${ }^{14}$ Es importante no pasar por alto que lo racional no debe ser interpretado aquí como equivalente de la racionalidad instrumental; es, por el contrario, según dijimos, una capacidad moral (cfr. Rawls 1993, pp. 50-51).

Diánoia, vol. LI, no. 56 (mayo 2006). 
premisa es una interpretación de las cargas del juicio. Según sostiene Rivera López, éstas pueden ser interpretadas como una transposición al terreno moral de la concepción falibilista ${ }^{15}$ ampliamente difundida en la epistemología de la ciencia especialmente a partir de trabajos como los de Karl Popper. ${ }^{16}$

Según Rivera López, el falibilismo no nos comprometería con el escepticismo moral: "lo único que afirma es que existe un límite máximo de credibilidad en la propia doctrina comprensiva, que es más bajo que el de la verificación o prueba concluyente. Esto significa que, aun aquellos que creen firmemente, tendrán que admitir que pueden estar equivocados" (Rivera López 1997, p. 62). De igual modo que en el caso de la ciencia, donde admitir que no es posible la verificación de una teoría no implica necesariamente la adopción de una postura escéptica

${ }^{15}$ La identificación entre cargas del juicio y falibilismo moral que propone Rivera López puede ser objetada. De hecho, Rawls parece rechazarla de forma explícita al sostener que las cargas del juicio se limitan a "enumerar algunas de las circunstancias que hacen que el acuerdo político en el juicio, y especialmente en los juicios sobre las doctrinas comprensivas, sea mucho más difícil" y que su planteamiento "no argumenta en favor de la duda y la incertidumbre [...] respecto de nuestras creencias" (Rawls 1993, p. 63). La posición de Rawls incluye la posibilidad de que las personas estén plenamente convencidas, sin resquicio alguno de duda, de la verdad o corrección de sus doctrinas comprensivas. El falibilismo moral defendido por Rivera López rechaza precisamente la legitimidad de esa posibilidad. No profundizaré esta posible línea de crítica al planteamiento de Rivera López, dado que el argumento que discutiré no depende en forma decisiva de la referida interpretación de las cargas del juicio. Como resultará claro a la luz de la reconstrucción desarrollada a lo largo del presente trabajo, la premisa que realmente utiliza Rivera López en su argumentación es el falibilismo moral.

${ }^{16}$ Podría objetarse a Rivera López que al apelar a las cargas del juicio está introduciendo desde el principio la idea de razonabilidad en las premisas de su argumento, dado que Rawls las presenta como parte de dicha idea. La respuesta de Rivera López a este tipo de objeción es que las cargas del juicio no contienen en sí mismas "ninguna connotación moral", equivalen a una tesis epistemológica cuya aceptación no implica por sí misma los compromisos (cooperación equitativa, tolerancia, instituciones, derechos y garantías liberales) asociados a la idea de razonabilidad que se quiere derivar (cfr. Rivera López 1997, p. 58, n. 8.) Justamente por esa razón, el argumento del autor no pretende derivar la razonabilidad tomando como única premisa el falibilismo moral, sino apelando a una combinación entre dicha premisa y una concepción de persona racional. Brian Barry sostiene una posición similar; también rechaza la posibilidad extraer conclusiones adversas a las pretensiones perfeccionistas tomando como única premisa el rechazo de la legitimidad de la certeza de que nuestra doctrina comprensiva es verdadera. Al igual que Rivera López, sostiene que una argumentación orientada a tal propósito deberá recurrir a premisas adicionales. Cfr. Barry 1995, p. 172. 
respecto del conocimiento teórico, este falibilismo no nos comprometería con el escepticismo en el campo práctico.

La tesis fundamental de Rivera López consiste en afirmar que la aceptación del falibilismo ético (es decir, la aceptación de que no podemos tener una certeza absoluta de que nuestra doctrina comprensiva sea verdadera) ofrece a toda persona racional —en el sentido especificado - fuertes razones para ser tolerante con las doctrinas y formas de vida diversas e incluso opuestas a la suya. Si estamos interesados en desarrollar nuestra facultad moral racional (i.e., nuestra capacidad para formular y llevar adelante una concepción del bien y un plan de vida), estaremos interesados en la verdad: todos tendremos interés en que nuestra concepción de la buena vida sea verdadera (que sea realmente una concepción de la buena vida), aunque, si aceptamos las cargas del juicio, reconozcamos que no es posible tener una certeza plena de ello. Si tenemos este interés por encontrar la verdad y reconocemos las cargas del juicio (lo que es equivalente a aceptar el falibilismo moral), tendremos buenas razones para que se garantice la mayor libertad posible para que las personas desarrollen y expresen sus puntos de vista. No tendremos derecho a suprimir otros puntos de vista que no coincidan con el nuestro, porque podríamos estar equivocados y, al suprimirlos, tal vez estaríamos privándonos de un punto de vista que podría sernos útil en nuestra búsqueda de la perspectiva verdadera. ${ }^{17}$

Al margen del uso del vocabulario rawlsiano y las referencias al falibilismo popperiano, el núcleo del argumento de Rivera López es prácticamente idéntico a uno de los clásicos argumentos propuestos por John Stuart Mill en defensa de la libertad de expresión. Mill sostiene en On Liberty que "la peculiaridad del mal que consiste en impedir la expresión de una opinión es que se comete un robo a la raza humana" (Mill 1975, p. 24). La censura es contraproducente para los propios intereses del que la promueve, para su interés básico en realizar los mejores juicios posibles en relación con la buena vida, porque, dado que somos

\footnotetext{
${ }^{17}$ En este punto, Rivera López recurre nuevamente a la comparación con la ciencia: "Si aceptamos que las teorías científicas son conjuntos de hipótesis o conjeturas, pero estamos interesados en encontrar la teoría verdadera, tenemos buenas razones para escuchar atentamente teorías adversarias a la nuestra y, por lo tanto, que se consagre un derecho a exteriorizar y escuchar opiniones científicas" (Rivera López 1997, p. 66). El paralelismo al que recurre el autor entre concepciones del bien y teorías científicas puede ser objeto de críticas desde diversas perspectivas. Me abstendré de realizar objeciones a este modo de proceder de Rivera López — sin que ello implique un juicio contrario a la posible pertinencia de tales objecionesdado que considero viable criticar su argumentación sin cuestionar tales supuestos.
}

Diánoia, vol. LI, no. 56 (mayo 2006). 
seres falibles, nadie puede descartar que al suprimir creencias o prácticas -ya que podrían ser correctas o valiosas- se esté privando tanto a sí mismo como a los demás "de la oportunidad de cambiar el error por la verdad" (Mill 1975, p. 24).

Ahora bien, Rivera López afirma que al aceptar las implicaciones de su argumentación nos comprometemos, simultáneamente, con la adhesión a una concepción política liberal que garantice para todos los ciudadanos una serie de derechos básicos inalienables, tales como la libertad de expresión, de participación política, etc., como los que quedan garantizados en el primer principio de justicia de la teoría de Rawls (cfr. Rivera López 1997, pp. 73-74). El propósito del argumento es, según declara, "plantear el problema ('de siempre') de la fundamentación moral de ciertos deberes básicos que todo individuo (y el Estado) asume en una sociedad, en términos generales, liberal" (Rivera López 1997, p. 54). Rivera López no presenta su propuesta como una defensa de la tesis de la neutralidad estatal, sino como un argumento "a favor del deber de tolerancia o respeto por concepciones del bien diversas" (Rivera López 1997, p. 54). El concepto de tolerancia es menos exigente que el de neutralidad. Podemos describir como "tolerante" un Estado que se abstiene de perseguir o censurar doctrinas y formas de vida que sus funcionarios juzgan carentes de valor pero que, sin embargo, no cumple con la tesis de la neutralidad, dado que, por ejemplo, promueve no coercitivamente ciertas concepciones del bien en razón de su supuesto valor intrínseco.

Hay dos cuestiones básicas que será necesario examinar. En primer lugar, debemos determinar el alcance del argumento de Rivera López. Bajo el supuesto de que se trate de un argumento sólido, ¿es capaz de superar los objetivos de su autor y ofrecer una defensa de la tesis de la neutralidad estatal, o meramente del deber del Estado de ser tolerante con las doctrinas comprensivas que no gozan de la adhesión o la simpatía de los grupos mayoritarios dentro de la sociedad? ¿Qué tipos de políticas perfeccionistas permite impugnar? La segunda cuestión básica consiste en determinar si esta propuesta cumple, al menos, con las metas explícitas del autor. ¿Se trata, en verdad, de un argumento consistente?

En las páginas siguientes presentaré una argumentación en tres pasos. El primero (a) apunta a demostrar que la argumentación de Rivera López es insuficiente como defensa de la tesis de la neutralidad. Aún así, podría quedar abierta la posibilidad de que ésta fuera exitosa como justificación de un deber del Estado de ser tolerante con las diversas doctrinas comprensivas a las que se adhieren los ciudadanos, lo cual 
coincide con las intenciones del autor. En tal caso, el argumento examinado podría igualmente ser de gran valor como parte de una estrategia de defensa de la tesis de la neutralidad, en tanto que permitiría impugnar las formas más claramente objetables de política perfeccionista. Los dos pasos siguientes de la objeción que desarrollaré tienen como meta bloquear esta última posibilidad, demostrando (b) que la propuesta de Rivera López realmente no ofrece razones para renunciar a la pretensión de prohibir a través del poder coercitivo del Estado las doctrinas comprensivas y las actividades que juzgamos erróneas o perniciosas, y (c) que es, en última instancia, internamente inconsistente.

Para comenzar, es necesario aclarar algunas de las implicaciones de las premisas que toma Rivera López como punto de partida. Ya conocemos las consecuencias de la aceptación del falibilismo: nunca podremos afirmar con certeza absoluta la verdad de nuestra doctrina; sin embargo, es muy importante prestar atención a implicaciones del concepto de "persona racional" que desempeñan un papel clave en la argumentación que estamos considerando. En el planteamiento de Rivera López, ser una persona racional entraña, entre otras cosas, poseer un "interés racional" en la verdad de la doctrina comprensiva que se profesa. Esto se debe a que "cualquier individuo racional está interesado en hallar o acercarse a la doctrina moral o religiosa correcta" y a que "la percepción de que tomamos decisiones correctas en esos ámbitos es indispensable para otorgar sentido a nuestra vida". ${ }^{18}$ Lo que no debe ser pasado por alto es que carecería de sentido estar interesado de este modo en la verdad -i.e., racionalmente interesado- si no fueran posibles no sólo las diferencias de hecho en la certeza con la que distintos sujetos afirman una doctrina (esto podría depender meramente del temperamento y la personalidad de los individuos o de sus caprichos), sino diferencias basadas en la capacidad de discriminar por medio de razones, de justificar o apoyar a partir de argumentos que ciertas doctrinas son más plausibles que otras. Para que sea posible, desde esta perspectiva, tener la percepción de que tomamos decisiones correctas en relación con nuestro plan de vida, debemos tener, ya que la verificación es imposible, al menos, criterios racionales para justificar nuestra idea de que

${ }^{18}$ Rivera López 1997, p. 66. Las afirmaciones que acabo de citar (en esta nota y la precedente) desempeñan un papel clave en la argumentación del autor y resultan plenamente adecuadas y coherentes con los rasgos de la estrategia consecuencialista que hemos descrito en la introducción de este trabajo. Una de las metas de la argumentación que desarrollo en las páginas siguientes apunta a mostrar que Rivera López se ve obligado a asumir posiciones incompatibles con estas tesis, lo cual genera un inconsistencia interna en su planteamiento.

Diánoia, vol. LI, no. 56 (mayo 2006). 
nos aproximamos a la verdad o mejoramos en algún sentido nuestras posibilidades de realizar elecciones correctas. ${ }^{19}$ De lo contrario, la idea de que tenemos un interés en la verdad pierde todo sentido y, en consecuencia, las razones para ser razonables y tolerantes desaparecen. La posibilidad de una "búsqueda racional de la verdad" es inseparable de la existencia de criterios racionales para distinguir entre creencias implausibles, plausibles, muy plausibles, etc. Sin tales criterios, la idea de progreso cognitivo, esencial a la concepción de persona racional involucrada en el argumento de Rivera López, perdería todo sentido.

Tras estas aclaraciones, podemos proceder a presentar las objeciones al argumento de Rivera López.

A) La tesis falibilista, tomada en sí misma, no da razones para la acción; es decir, no permite justificar la elección de un curso de acción determinado frente a otras alternativas disponibles; por consiguiente, no ofrece a los agentes justificación alguna para escoger abstenerse de apoyar políticas perfeccionistas basadas en sus creencias comprensivas frente a la alternativa de apoyarlas. En situaciones reales no puede evadirse la necesidad de tomar decisiones y actuar, y tales decisiones y acciones siempre se basan en conjuntos particulares de creencias. La tesis falibilista según la cual debo reconocer que nunca será posible alcanzar la verificación de una doctrina comprensiva, siendo consecuentes, se predica de todas las creencias que poseo $;^{20}$ es decir, de todas las creencias en las que puedo basar mis decisiones y cursos de acción. Ahora bien, si la tesis falibilista diera por sí misma razones para actuar, debería permitir identificar alguna clase de diferencia entre aquellas creencias que apoyan la decisión de realizar la acción $A$ y las que apoyan realizar la acción alternativa $B$; debería permitir justificar la afirmación de que alguno de los conjuntos de creencias en cuestión es más dudoso, menos confiable o más probablemente erróneo que el otro. Sin embargo, la tesis falibilista no permite establecer esta clase de diferenciación, dado que dice exactamente lo mismo de las creencias en las que se apoya la decisión de realizar la acción $A$ y las que apoyan la decisión de realizar $B$. Según vimos, todo lo que afirma de ambas es que no podemos tener la certeza plena de que sean verdaderas o correctas.

\footnotetext{
${ }^{19}$ El concepto de persona racional involucrado en el argumento de Rivera López implica la tesis de que es posible realizar juicios objetivos en relación con la cuestión de la buena vida.

${ }^{20} \mathrm{Si}$ aceptamos el falibilismo en el plano práctico, es de esperarse que lo aceptemos en el teórico. Por otra parte, esa acepción incluso ya está implícita en el hecho de que prediquemos el falibilismo de doctrinas comprensivas religiosas, filosóficas y morales, dada la amplitud de temas que suelen involucrar.
} 
La razón para suspender un curso de acción o una decisión (como la de apoyar una política perfeccionista o cualesquiera otras) no puede ser meramente el reconocimiento de que existe la posibilidad de estar equivocados, sino que debe fundarse en consideraciones adicionales capaces de producir dudas acerca del conjunto determinado de creencias en el que apoyamos dicho curso de acción. Como correctamente sostenía J.L. Austin, "estar consciente de que puedes estar equivocado no significa meramente ser consciente de que eres un ser humano falible: significa que tienes alguna razón concreta para suponer que estás equivocado en ese caso" (Austin 1970, p. 98). Por ejemplo, un científico no abandona una teoría por el hecho de que reconozca que es imposible verificarla (i.e., nunca podrá descartar la posibilidad de que sea falsa), eso se predica de toda teoría; si decide abandonarla es porque hay razones (surgidas de criterios consensuados por la comunidad científica: datos apropiadamente documentados, experimentos, etc.) que permiten refutar esa teoría en particular o que la muestran menos prometedora que otras alternativas disponibles. Algo paralelo debe darse en el caso que estamos considerando: el hecho de que un sujeto acepte la tesis falibilista no es suficiente para que renuncie al intento de promover su doctrina a través del poder estatal; antes bien, debería ser posible sembrar en él dudas concretas sobre la plausibilidad del conjunto determinado de creencias (asociado a dicha doctrina comprensiva) en que apoya tal pretensión y, según vimos, la tesis falibilista no puede producir tales dudas por sí sola.

Otra variante de las dificultades referidas podría ser presentada del siguiente modo. Consideremos dos proposiciones:

1) Poseer la facultad racional, entendida en el sentido estipulado por Rawls en Political Liberalism, constituye un rasgo esencial de las personas concebidas como agentes morales.

2) Dado que Cristo es el hijo de Dios, los valores morales difundidos por él son los correctos.

Si es lícito extraer alguna implicación práctica o política de la proposición 1), como pretende Rivera López, será igualmente lícito hacerlo en el caso de 2). Esto se debe a que la premisa falibilista dice exactamente lo mismo de cada una de ellas: que nunca podremos descartar con certeza la posibilidad de que sea falsa. O bien la tesis falibilista constituye un impedimento para extraer implicaciones políticas en ambos casos, y el argumento de Rivera López debe renunciar a su otra premisa, o bien no constituye un impedimento en ninguno de ellos.

Diánoia, vol. LI, no. 56 (mayo 2006). 
Podemos concluir que la tesis falibilista no ofrece por sí misma razones para suspender la decisión de promover a través de políticas estatales (ya sea coercitiva o no coercitivamente) la concepción del bien a la que nos adherimos o las prácticas que juzgamos intrínsecamente valiosas. Resulta claro que tampoco da cuenta de una de las ideas fundamentales de la tradición liberal, la convicción de que ciertos ideales morales fundamentales, ampliamente compartidos, constituyen una base más apropiada de justificación de las políticas estatales que doctrinas comprensivas religiosas. La proposición 1) representa un ejemplo de tales ideales compartidos, mientras que 2) representa un caso del segundo tipo de creencias comprensivas. Sin embargo, la tesis falibilista no permite establecer ninguna diferencia entre ellas.

Podría sostenerse que la situación cambia en cuanto combinamos el falibilismo moral con la premisa del interés racional en la verdad y una hipótesis adicional relativa a los efectos de las políticas perfeccionistas coercitivas. Puede sostenerse que existe una alta probabilidad de que dichas políticas conduzcan a la desaparición de las creencias y prácticas incompatibles con las que resulten favorecidas por el Estado. Si esto es correcto, dado que, como consecuencia de la tesis falibilista, debemos reconocer que nunca podremos descartar la posibilidad de estar equivocados, tampoco podremos descartar que los efectos de las políticas perfeccionistas coercitivas sean perjudiciales para nuestro interés en hacer juicios correctos acerca de la cuestión de la buena vida; no podemos descartar que alguna de las concepciones que dejarán de estar disponibles como consecuencia de ese tipo de políticas perfeccionistas podrían sernos útiles en la tarea de aproximarnos a la concepción verdadera. Supongamos, en forma provisional, que las consideraciones anteriores son consistentes; aun en ese caso es fácil notar que no constituyen una objeción contra las políticas perfeccionistas que se abstienen de apelar al uso de la fuerza. La promoción estatal no coercitiva de ciertas concepciones del bien y actividades (a través de propaganda, campañas, ofrecimiento de estímulos económicos, etc.) no parece tener como efecto, ni necesario ni altamente probable, la desaparición de las restantes alternativas. Éstas podrían ser promovidas por asociaciones intermedias, quizá con tanto éxito como el obtenido por Estado o, al menos, con el suficiente como para que no desaparezcan. Por otra parte, una política semejante, dada la ausencia de prohibiciones y persecución, no privaría a los individuos, al menos en forma directa o explícita, de la libertad para modificar sus creencias y cursos de acción. Si resulta implausible sostener que las políticas perfeccionistas no coercitivas tendrán como consecuencia previsible la desaparición de las concepciones 
comprensivas alternativas a la concepción o concepciones promovidas por el Estado, las razones para impugnarlas se desvanecen. ${ }^{21}$ Como consecuencia de ello, el argumento falibilista no resulta suficiente para justificar la tesis de la neutralidad.

B) Ahora intentaré demostrar que la combinación de la tesis falibilista y la premisa relativa al interés racional en la verdad moral no ofrece, contra lo que concedimos provisionalmente en el punto anterior, razones para dejar de lado la prohibición de las doctrinas rivales de la que se profesa. Hagamos un experimento mental. Imaginemos que es posible acceder a un dato de nuestro futuro: sabemos que abandonaremos (o intentaremos abandonar) la doctrina comprensiva a la que nos adherimos en el presente y que abrazaremos alguna de las doctrinas incompatibles con ella disponibles en nuestra sociedad. Supongamos, también, que está en nuestro poder tanto modificar como dejar inalterado este hecho, que disponemos de la capacidad para prohibir todas las doctrinas comprensivas religiosas, filosóficas o morales incompatibles con aquella que suscribimos en el presente. Nuestro conocimiento de que abrazaremos una doctrina incompatible con la que profesamos en el presente es momentáneo, pronto olvidaremos que lo tuvimos, con lo cual si no actuamos para modificar ese hecho futuro el cambio de creencias se producirá inexorablemente. Debemos tomar una decisión al respecto: o prohibimos dichas doctrinas y modificamos nuestro futuro o nos abstenemos de hacerlo. Existen tres posibilidades: i) Tanto la doctrina que profesamos en el presente como la que profesaremos en el futuro son falsas; en tal situación, obviamente ninguna de las dos posibilidades (prohibir o no prohibir) promueven nuestro interés racional en aproximarnos a la verdad. ii) La doctrina a la que nos adherimos en el presente es verdadera y la que abrazaremos en el futuro, incompa-

\footnotetext{
${ }^{21}$ Podría contraargumentarse que es difícil descartar con certeza que la promoción no coercitiva de una concepción del bien o de un conjunto de ellas por parte del Estado tenga un fuerte impacto sobre alguna de las concepciones restantes y conduzca a su desaparición, del mismo modo que en el caso de las políticas perfeccionistas coercitivas, de modo que también tendríamos razones para dejar de lado las políticas perfeccionistas no coercitivas. Creo, sin embargo, que no hay modo de saber con un grado de seguridad aceptable si esa hipótesis es o no correcta. Muy probablemente cuestiones empíricas relativas a las características particulares de la cultura de la sociedad en cuestión serán, en cada caso particular, decisivas al respecto. Puesto que la plausibilidad del argumento de Rivera López como defensa de la tesis de la neutralidad dependería, en última instancia, de una hipótesis sumamente controvertida acerca de las consecuencias de las políticas perfeccionistas no coercitivas, podemos concluir que, en el mejor de los casos, su atractivo es muy limitado.
} 
tible con ella, es, por consiguiente, falsa. En este caso nuestro interés en la verdad será resguardado por la prohibición de dicha doctrina, lo cual impedirá que en el futuro caigamos en el error. Recordemos que, siguiendo el experimento mental propuesto, sabemos fehacientemente que de no prohibir la doctrina en cuestión, nos adheriremos a ella en el futuro. iii) Nuestra doctrina actual es falsa y la alternativa futura, verdadera. En este caso, nuestro interés en la verdad será satisfecho por el rechazo de la prohibición, en tanto éste hará posible que en el futuro alcancemos o nos aproximemos a la verdad. Si el argumento de Rivera López funciona, la combinación entre sus dos premisas - que es, a fin de cuentas, todo lo que nos ofrece- debería ser capaz de ofrecernos alguna razón para rechazar la alternativa que involucra la prohibición. Ahora bien, dejando de lado la posibilidad de que ambas doctrinas sean falsas, si aceptamos la tesis falibilista, debemos reconocer que nunca podremos saber con plena certeza cuál de las dos doctrinas incompatibles, la que defendemos en el presente o la que abrazaremos en el futuro, es verdadera: todo lo que podemos afirmar al respecto es que ninguna de las dos podrá ser jamás verificada. Una tesis que, como la falibilista, se aplica igualmente a cualquier conjunto de creencias en las que podemos basar nuestras decisiones relativas a la elección de cursos de acción, no ofrece ninguna guía para elegir entre las diversas alternativas, porque dice exactamente lo mismo de cualquiera de ellas. En consecuencia, si sólo contamos exclusivamente con las premisas del argumento de Rivera López como bases para tomar nuestra decisión (i.e., el interés en la verdad y la tesis falibilista) no hay forma de saber cuál de los dos cursos de acción del experimento mental, prohibir o no prohibir, produce el efecto deseado y maximiza nuestras posibilidades de aproximarnos a la verdad. Cualquiera de ellos podría tener como efecto alejarnos o aproximarnos a la verdad, nunca lo sabremos; por lo tanto, el argumento de Rivera López no ofrece ninguna razón para elegir racionalmente entre ambos cursos de acción. Sin embargo, como dijimos, si tal argumento funcionara, debería ser capaz de ofrecer apoyo al rechazo del curso de acción que involucra la prohibición de la doctrina comprensiva que suscribiremos en el futuro. El argumento debería darnos razones para creer que evitar la prohibición es la mejor estrategia para maximizar nuestras oportunidades de acertar, realizar juicios correctos o aproximarnos a la verdad. Lo que muestra el experimento mental es que si nos atenemos a las premisas del argumento, no hay forma de saber qué acción (prohibir o no prohibir) satisface mejor muestro interés en aproximarnos a la verdad. Cualquier decisión se convierte en una apuesta a ciegas. 
La situación sería distinta si dispusiéramos de criterios para afirmar que una de las dos doctrinas alternativas es más probablemente verdadera que la otra, o si fuera posible refutar una de ellas. Si fuéramos capaces de refutar la doctrina a la que nos adherimos en el presente o si dispusiéramos de criterios no controvertidos que nos permitieran detectar en ella debilidades que no pudieran ser atribuidas a las doctrinas rivales, está claro que tendríamos buenas razones para rechazar la prohibición de dichas doctrinas: al abrazar en el futuro alguna de ellas, maximizaríamos nuestras posibilidades de aproximarnos a la verdad. De igual modo, si pudiéramos refutar la doctrina que, siguiendo nuestra hipótesis, sabemos que profesaremos en el futuro, tendríamos buenas razones para considerar justificada su prohibición en razón de nuestro interés en la verdad. ${ }^{22}$

C) Paradójicamente, no ganaríamos nada si dispusiéramos de los criterios adicionales cuya ausencia causa los problemas precedentes. Hay una diferencia muy importante entre el falibilismo moral que nos propone Rivera López y el falibilismo científico. En el falibilismo popperiano, la posibilidad de refutación de la hipótesis desempeña un papel central para explicar el progreso científico. Dicho progreso consiste en un alejamiento del error, posibilitado justamente por el hecho de que los científicos son capaces de desechar en forma justificada ciertas hipótesis. Sin embargo, de ser posible la refutación de doctrinas comprensivas, aunque ganáramos un criterio que diera sentido en este campo a la idea de aproximación racional a la verdad, perderíamos la razón fundamental por la cual considerábamos que debíamos ser tolerantes y que debíamos renunciar a la pretensión de prohibir las doctrinas incompatibles con la que profesamos. Restringiéndonos a la lógica del argumento de Rivera López, si estamos justificados en creer que una doctrina ha sido refutada, que se ha probado su falsedad, no hay razones para continuar tolerándola, sencillamente porque no nos prestará

${ }^{22}$ Un contraargumento consistiría en la idea de que una mayor cantidad de cambios de doctrina - posibilitados por el rechazo a prohibir las doctrinas incompatibles con las que en cada caso defendamos- maximizará nuestra probabilidad de acceder a la verdad. Sin embargo, afirmar justificadamente que hay un aumento en la probabilidad de aproximarnos a la verdad en el paso de una doctrina a otra no depende de la cantidad de veces que cambiemos de doctrina; ese cambio, realizado a ciegas, no aporta nada a nuestro conocimiento. Todo depende de la posibilidad de poseer criterios adecuados para fundamentar la idea de que la doctrina por la que optamos es más plausible que las otras, o bien, en clave popperiana, que nos alejamos del error al refutar una de ellas (mientras que aquella a la que nos adheriremos subsecuentemente resiste, por el momento, la refutación).

Diánoia, vol. LI, no. 56 (mayo 2006). 
en el futuro ninguna ayuda para cumplir con nuestra meta de aproximarnos a la verdad moral (cfr. Rivera López 1997, p. 69). Rivera López intenta evitar esta dificultad afirmando que la refutación de doctrinas comprensivas es inviable. Desde su perspectiva, no sólo debemos aceptar que nunca podremos estar completamente seguros de que nuestra doctrina es verdadera, tampoco podremos estar seguros de que alguna de las doctrinas disponibles haya sido refutada. ${ }^{23}$ La tesis de la inviabilidad de la refutación implica la aceptación de que nunca podremos estar seguros de que aquello que nuestra doctrina comprensiva nos permite identificar como falso, absurdo, despreciable, etc., sea realmente falso, absurdo o despreciable. Implica admitir que existe la posibilidad, por remota que nos parezca, de que las doctrinas más absurdas a nuestros ojos, aquellas que son no sólo diferentes, sino incluso incompatibles en cuestiones fundamentales con la que defendemos, podrían ser correctas o verdaderas. Si esto es así, la idea de que poseemos un interés racional en la verdad o en aproximarnos a ella pierde todo sentido, porque la verdad se habría vuelto, además de inalcanzable, irreconocible; irreconocible, justamente porque nunca podremos descartar que una doctrina completamente diferente de la que sostenemos podría ser verdadera. Esto implica, además, que nunca será posible descartar que el camino que estamos recorriendo, en vez de aproximarnos, tal vez nos aleje de la verdad. En estas condiciones queda bloqueada toda posibilidad de disponer de criterios para discriminar entre doctrinas implausibles, plausibles, etc., lo cual se debe, nuevamente, a que habrá que admitir que hasta la doctrina más absurda a la luz de nuestras creencias actuales podría ser verdadera. Una meta semejante, no sólo inalcanzable, sino irreconocible, ¿puede ser realmente concebida como una "meta"? ¿No sería esto algo tan absurdo como afirmar que estamos "apuntando" a un blanco invisible? En estas condiciones, que equivalen a la adopción de una posición escéptica o relativista, es cierto que nadie podría sostener que una concepción comprensiva debe ser prohibida porque ha sido refutada y, por lo tanto, ya no presta ninguna utilidad para satisfacer nuestro interés de hallar la verdad o de acercarnos a ella. El problema es que tal interés pierde también todo sentido, se vuelve completamente irrealizable y con él desaparecen las razones que podían aducirse desde

${ }^{23}$ Según escribe Rivera López: "debe tenerse en cuenta que, incluso en el plano de la ciencia, y aun cuando existe la posibilidad de la contrastación empírica de afirmaciones singulares (cosa que en el caso de la moral no se da), la posibilidad de refutación definitiva de una teoría es más una posibilidad lógica que real. En el campo de las teorías morales y religiosas, esta posibilidad es todavía más remota" (Rivera López 1997, p. 70). 
esta perspectiva para abstenernos de prohibir las doctrinas incompatibles con la que de hecho profesamos. Una vez eliminada la premisa del interés en la verdad, queda únicamente en pie la tesis falibilista, que, como sabemos, no da razones para la acción y, en particular, no ofrece por sí misma razón alguna para ser tolerantes.

Para finalizar esta sección quisiera responder brevemente una posible objeción a la argumentación precedente que podría formularse en los siguientes términos.

La tesis falibilista afirma que no podemos tener la certeza de la verdad de ninguna doctrina comprensiva. De ello no se sigue que, por lo tanto, todas las doctrinas comprensivas estén igualmente justificadas. Aunque no podamos tener la certeza de ninguna de ellas, podemos tener mejores razones a favor de alguna en comparación con otras. En segundo lugar, la tesis falibilista no tiene por qué ofrecer una guía para elegir entre doctrinas; la guía, por así llamarla, serían las razones que tenemos a favor de cada doctrina. En tercer lugar, del hecho de que no tengamos certeza sobre la verdad de ninguna doctrina comprensiva no se sigue que la verdad se haya vuelto irreconocible. ${ }^{24}$

En relación con los puntos primero y tercero, debo decir que mi argumentación en ningún momento afirma que suscribir la tesis falibilista, tomada en sí misma, equivalga a sostener que todas las doctrinas comprensivas estén igualmente justificadas, o a asumir una posición escéptica, o a eliminar la idea de progreso cognitivo. Lo que se sostiene es que tales resultados son causados por la combinación de la tesis falibilista con el rechazo de la viabilidad de la refutación. En mi argumentación sostuve que introducir esta última tesis equivale a eliminar la posibilidad de hablar de progreso cognitivo y, como sabemos, la factibilidad de tal progreso es esencial para el planteamiento de Rivera López. ¿Qué clase de progreso cognitivo podría haber si nunca fuera posible descartar en forma justificada ninguna creencia? ¿Qué clase de proceso racional de aproximación a la verdad podría haber si siempre debo reconocer que las creencias que considero más implausibles se encuentran en pie de igualdad, como candidatas a ser verdaderas, con las que considero más sólidas? El resultado de esta situación no puede ser otro que el reconocimiento de que la supuesta diferencia entre creencias plausibles e implausibles tiene un estatus puramente subjetivo; es decir, de la adopción de una forma de escepticismo. Como resultará claro, la fuente de este resultado no es la tesis falibi-

\footnotetext{
${ }^{24}$ Agradezco esta objeción a uno de los árbitros anónimos del presente artículo.
} 
lista misma, sino su combinación con la tesis de la inviabilidad de la refutación. ${ }^{25}$

En relación con el segundo punto de la objeción, la respuesta es similar a la precedente. Mi argumentación tampoco involucra la idea de que la tesis falibilista deba ofrecer criterios racionales para escoger entre creencias comprensivas alternativas. Lo que se sostiene es (1) que ni la tesis falibilista ni, en general, el argumento de Rivera López los ofrece, (2) que la noción de progreso cognitivo involucrada en el argumento presupone que tales criterios estén disponibles o sean viables - provengan de donde provengan-, pero que, al la vez, (3) la argumentación del autor necesita neutralizarlos o eliminarlos - como pone en evidencia el rechazo de la viabilidad de la refutación-. La inconsistencia del planteamiento de Rivera López radica, como hemos visto, en la incompatibilidad entre (2) y (3).

III

Ahora examinaremos una versión del argumento falibilista desarrollada por Will Kymlicka. Intentaré probar que las dificultades identificadas en el argumento de Rivera López se aplican de modo similar en este caso. La propuesta de Kymlicka es también una reformulación de uno de los argumentos clásicos de Mill a favor de la libertad de expresión. En On Liberty, Mill sostiene que la libertad de toda persona para exponer, discutir y contradecir cualquier creencia es una condición necesaria para que seamos capaces - $\mathrm{o}$ al menos plenamente capaces- de realizar juicios racionales y de aproximarnos a la verdad tanto en cuestiones

${ }^{25}$ Debe quedar claro que en ningún momento he cuestionado la formulación del falibilismo moral ofrecida por Rivera López. En todos los casos se entiende "tesis falibilista" o "falibilismo moral" como equivalente a "negación de la legitimidad de la certeza plena en la afirmación de la verdad de nuestras creencias comprensivas". Cuando afirmo que el planteamiento del autor conduce a una posición escéptica, contraproducente para sus propios propósitos, como acabo de señalar en el texto, no estoy sosteniendo que tal resultado derive de la adopción de la referida posición falibilista. Si se combinara el falibilismo con criterios del progreso cognitivo adecuados, como podría sostenerse que ocurre en uno de los modelos que toma el autor como punto de partida, el falibilismo popperiano, la derivación en un posición escéptica no tendría lugar. Quizá una aclaración adicional sea útil: se incurre en una confusión si no se distingue entre "la tesis falibilista" y "el argumento falibilista". La tesis falibilista es, como vimos, sólo una de las premisas de tal argumento. Afirmar que el argumento falibilista conduce a una posición escéptica no implica afirmar que la tesis falibilista sea en sí misma la causa de tal resultado. 
teóricas como prácticas. ${ }^{26}$ Kymlicka ha recurrido a esta línea de argumentación en tres de sus trabajos más significativos: Liberalism, Community and Culture (1989), Contemporary Political Philosophy (1990) y Multicultural Citizenship (1995). ${ }^{27}$ Según el autor, dado que "reconocemos que nuestros juicios actuales y pasados son falibles", ${ }^{28}$ debemos disponer de la libertad para cuestionar, revisar y modificar nuestras creencias "a la luz de cualquier información, ejemplos y argumentos que nos ofrezca nuestra cultura"; dicha libertad es una precondición indispensable para que podamos realizar nuestro "interés primordial en llevar adelante una buena vida". Como afirma Kymlicka:

los individuos deben disponer de las condiciones culturales que los conduzcan a adquirir conocimiento de diferentes puntos de vista acerca de la buena vida, y adquirir la habilidad de examinar y reexaminar inteligentemente esos puntos de vista. De ahí la tradicional preocupación liberal por la educación, la libertad de expresión, la libertad de prensa, la libertad artística, etc. Esas libertades nos vuelven capaces de juzgar qué es de valor en la vida del único modo en que tales cosas pueden ser juzgadas (i.e. explorando los diferentes aspectos de nuestra herencia cultural colectiva). ${ }^{29}$

La tesis adicional es que las políticas perfeccionistas constituyen un obstáculo para la satisfacción de dicha precondición; pues si el Estado afirma ciertas creencias acerca de la buena vida como verdaderas, promueve determinadas formas de vida o desalienta otras mediante sanciones, obstaculizará la posibilidad de que los ciudadanos lleven adelante en forma adecuada el proceso de revisión crítica de sus creencias.

Hay dos modos básicos de interpretar en qué consiste el valor de la libertad para revisar nuestros puntos de vista y modificar nuestras creencias y prácticas; puede atribuírsele un valor intrínseco, o bien valor instrumental. Aunque la primera interpretación ha sido considerada

${ }^{26}$ Cfr. Mill 1975, pp. 28-29. Según Mill, "la única manera que tiene el hombre de acercarse al total conocimiento de un objeto es oyendo lo que pueda ser dicho de él por personas de todas las opiniones, y estudiando todos los modos de que puede ser considerado por los diferentes caracteres del espíritu" (Mill 1975, p. 28). De hecho, continúa Mill, "las creencias en las que mayor confianza depositamos no tienen más salvaguardia para mantenerse que una permanente invitación a todo el mundo para que pruebe su carencia de fundamento" (Mill 1975, p. 28-29).

${ }^{27}$ Cfr. Kymlicka 1989a, pp. 11-13; 1990, pp. 203-204; 1995, pp. 81-82. La formulación del argumento que examinaremos no presenta ninguna diferencia o variante significativa en las tres obras citadas.

${ }^{28}$ Kymlicka 1989a, p. 11. Véanse también Kymlicka 1990, p. 203, y 1995, p. 81.

${ }^{29}$ Kymlicka 1989a, p. 13. Véanse también Kymlicka 1990, p. 204, y 1995, p. 81.

Diánoia, vol. LI, no. 56 (mayo 2006). 
con frecuencia la posición liberal típica, Kymlicka se inclina decididamente en favor de la segunda. Tanto en Liberalism, Community and Culture, como en Contemporary Political Philosophy, sostiene que no deberíamos valorar

la libertad de elegir nuestros proyectos por el bien mismo de la libertad, por el hecho de que la libertad sea lo más valioso del mundo. Más bien, nuestros proyectos y tareas son lo más importante de nuestras vidas, y son tan importantes que tendríamos que ser libres de revisarlos, si llegáramos a creer que no tienen el valor que les asignábamos [...]. La libertad de elección no es deseable por sí misma, sino como condición para alcanzar esos proyectos que tienen valor por sí mismos. ${ }^{30}$

Al presentar en Multicultural Citizenship el argumento falibilista que estamos examinando, el autor asume la misma posición. Sostiene que no debe interpretarse su afirmación de que hay que atribuir una "importancia fundamental" a la capacidad "de evaluar racionalmente nuestras concepciones de lo bueno a la luz de nueva información o experiencias, y de revisarlas si no merecen que sigamos ateniéndonos a ellas" (Kymlicka 1995, p. 81) como un compromiso con la tesis de que tal capacidad posea un valor intrínseco. Kymlicka afirma, en una nota que sigue a las líneas citadas, que no debemos confundir su posición con los ideales de autonomía de filósofos como Kant o Mill que, al margen de sus importantes contrastes, compartirían la valoración del ejercicio de la libertad de elección como un bien intrínseco. Por el contrario, su argumento introduciría "la pretensión más modesta según la cual la elección nos permite evaluar y aprender qué es bueno en la vida" (Kymlicka 1995, p. 213, n. 7). En el marco del argumento que estamos examinando, la capacidad de revisar y criticar nuestras creencias no es valorada por sí misma, sino por su capacidad para incrementar nuestras posibilidades de realizar juicios correctos acerca de lo bueno o valioso en la vida.

El hecho de que Kymlicka tome como punto de partida de su argumento esta concepción instrumental del valor de la libertad de elección puede resultar sorprendente, dado que ella parece abrir las puertas a las posiciones perfeccionistas que los liberales rechazan. Si el valor de nuestra capacidad para revisar y criticar las creencias y proyectos que suscribimos radica sólo, o por lo menos centralmente, en que mejora nuestras posibilidades de realizar juicios correctos o corregir errores,

\footnotetext{
${ }^{30}$ Kymlicka 1990, p. 209; las cursivas son mías. Véase también Kymlicka 1989a,
} p. 48. 
¿qué ocurre en el caso de aquellos sujetos que utilizan mal esa capacidad?, ¿qué ocurre con aquellos que al revisar críticamente sus proyectos terminan dejando de lado formas de vida valiosas por proyectos triviales o sin valor? ¿Debería ser limitada, en esas circunstancias, la libertad de los agentes para revisar sus creencias o modificar sus estilos de vida? A la luz de la concepción instrumental, una respuesta afirmativa a esta última pregunta parece inevitable. Por supuesto, la meta del argumento de Kymlicka es justificar el resultado opuesto. Su hipótesis es que al combinar la concepción instrumental del valor de la libertad de elección (compatible y probablemente afín a posiciones perfeccionistas) con una premisa adicional, la tesis falibilista, obtendremos una justificación de la posición liberal. Dicha posición, como sabemos, rechaza, dentro de los límites de la justicia, cualquier limitación de la libertad de los ciudadanos para revisar y modificar sus creencias y estilos de vidas. ${ }^{31}$

La otra premisa del argumento, la afirmación de que nuestros juicios son "falibles", es también susceptible de diversas interpretaciones, fundamentalmente en relación con su profundidad y alcance. Bajo una primera interpretación podríamos decir que reconocer que somos falibles significa simplemente que existe la posibilidad de que cometamos errores, en el sentido de que podemos equivocarnos al realizar un cálculo matemático complejo. Haciendo una analogía con la epistemología, se

${ }^{31}$ No debe pasarse por alto que la argumentación de Kymlicka constituye una forma de perfeccionismo indirecto. Su planteamiento suscribe las metas perfeccionistas y aspira partir de premisas aceptables para dichas posiciones. Como vimos, la idea central de esta estrategia es demostrar que el mejor modo de cumplir con el objetivo de promover imparcialmente el bien de todos los ciudadanos no es impulsando políticas que apunten directamente a tal propósito (políticas perfeccionistas directas), sino suscribiendo principios liberales. Hay tres razones por las cuales Kymlicka no apela a la concepción del valor intrínseco de la libertad de elección. La primera radica en que tal concepción es considerada con frecuencia como idiosincrásicamente liberal y concita el rechazo de la mayoría de los perfeccionistas. Tomarla como premisa del argumento falibilista le restaría eficacia frente a sus destinatarios (Kymlicka pretende convencer a los perfeccionistas, no a los que ya son liberales). La segunda razón es que la tesis del valor intrínseco de la libertad de elección ofrecería, de ser plausible, una defensa de las políticas liberales independiente de la premisa falibilista. Si el ejercicio de la libertad de elección es, en sí mismo, al margen de sus resultados, como decía Kymlicka, "lo más valioso del mundo" o un bien cuya pérdida resulta inadmisible, entonces las políticas estatales que limiten esa libertad nunca serán admisibles. Dada esa premisa, la apelación al falibilismo resulta innecesaria. La tercera razón es que, al menos en Liberalism, Community and Culture y Contemporary Political Philosophy, el autor cuestiona la plausibilidad de la concepción del valor intrínseco. Cfr. Kymlicka 1989a, pp. 49-50, y 1990, pp. 209-210.

Diánoia, vol. LI, no. 56 (mayo 2006). 
puede ser "verificacionista", creer que las leyes de las ciencias fácticas, como la física o la biología, pueden ser verificadas y reconocer este sentido de "falibilidad"; es decir, reconocer que, aunque podemos alcanzar un conocimiento seguro de ciertas cosas, el "error humano" es una posibilidad que no debe ser desestimada, aun cuando, tras un cuidadoso tratamiento del asunto en cuestión, pueda ser finalmente superado. De igual modo, podemos tener la certeza de que la doctrina comprensiva a la que nos adherimos es la correcta y reconocer, sin embargo, que podemos cometer errores, en última instancia corregibles, acerca de, por ejemplo, sus implicaciones prácticas cuando la aplicamos a un caso particular.

La segunda interpretación sería la transposición del falibilismo popperiano a este campo. Así como las leyes de las ciencias fácticas no pueden ser verificadas y, por lo tanto, siempre existe la posibilidad de que nuevos datos o experiencias nos demuestren que son falsas, nuestra falibilidad implica en este caso que nunca podremos tener la certeza de que las creencias acerca de la buena vida a las que nos adherimos son verdaderas, de modo que la posibilidad de error es ineliminable.

Examinemos las dificultades involucradas en el argumento cuando combinamos la concepción instrumental del valor de la libertad para cuestionar y modificar nuestras creencias y formas de vida con la primera interpretación de "falibilidad". Para ello hagamos una variación del tipo de experimento mental que desarrollé como segundo paso de mi objeción al argumento falibilista de Rivera López. Como sabemos, en la concepción instrumental el valor de la libertad para revisar nuestras creencias derivaría centralmente de su capacidad para maximizar nuestras oportunidades de realizar juicios correctos acerca del valor de nuestras actividades y de nuestro plan de vida. Supongamos que yo sé que en el futuro, de no existir obstáculos para ello, cambiaré radicalmente mis creencias, es decir, que sostendré puntos de vista incompatibles con los que ahora juzgo verdaderos. ¿Debería apoyar un Estado que me garantice la libertad para revisar mis creencias, con lo cual en el futuro nada impedirá que se produzca el cambio de creencias, o bien debería apoyar un Estado que ponga límite a esa libertad, impidiendo el cambio? Dada la concepción instrumental, la respuesta depende fundamentalmente del efecto del cambio de creencias. ${ }^{32}$ Por

${ }^{32}$ Como señala Hurka, correctamente a mi juicio, dada la concepción instrumental y el correlativo rechazo de la tesis del valor intrínseco de la libertad de elección que caracteriza la posición de Kymlicka, el valor de la revisión de nuestras creencias dependerá de su papel como apoyo o ayuda en la elección de concepciones del bien que contribuyan realmente a que vivamos una buena vida. Cfr. Hurka 1995, p. 51. 
más que reconozca el valor de la libertad para cuestionar mis creencias durante el proceso que conduce a la formulación de un plan de vida o de las deliberaciones relativas a cómo llevarlo adelante eficientemente, si dicha libertad permite que abandone un plan de vida realmente valioso por uno carente de valor, será de mi interés que dicha libertad sea limitada. Kymlicka reconoce en forma explícita que tanto los individuos como el Estado son capaces de hacer juicios morales objetivamente correctos. ${ }^{33} \mathrm{Si}$ el gobierno puede realizar tales juicios correctos, una vez realizados, la libertad para que las personas los rechacen, dado que abre la posibilidad de que reemplacen puntos de vista correctos por opiniones erróneas, podría, razonablemente, ser considerada contraproducente desde una perspectiva consecuencialista. En esta misma línea, Hurka afirma que

si mis creencias actuales acerca de lo bueno son verdaderas, y la revisión pudiera reemplazarlas por creencias falsas, la revisión me produciría un daño. Si en esas circunstancias el Estado me disuadiera de revisar mis creencias, ya sea coercitiva o no coercitivamente, eso sería bueno para mí. Entendido correctamente, como lo entiende Kymlicka, el valor de revisar las propias creencias no puede dar apoyo a un edicto de supresión [blanket ban] del perfeccionismo estatal. (Hurka 1995, p. 51)

Quizá sea plausible argumentar que si adoptamos la segunda interpretación de "falibilidad", las objeciones precedentes pueden ser, al menos parcialmente, neutralizadas. Admitir que somos falibles en dicho sentido equivale a reconocer que nunca podremos descartar con certeza la posibilidad de que nuestras creencias más firmes acerca de la buena vida sean falsas. Si esto es así, parece haber buenas razones para no cerrar nunca la posibilidad de revisar y modificar nuestros juicios. Si el Estado impidiese que revise y abandone una creencia, basado en el supuesto de que tal creencia es correcta, dicha política podría tener efectos desastrosos, dado que no seríamos capaces de descartar que la creencia en cuestión fuese, por el contrario, errónea. Sin embargo, este tipo de consideraciones deben enfrentar inconvenientes semejantes a los que señalé en el caso del argumento de Rivera López.

\footnotetext{
${ }^{33}$ Según sostiene Kymlicka, "compartimos lo suficiente con los otros que están a nuestro alrededor como para que un gobierno perfeccionista bien intencionado, atendiendo al conocimiento y la experiencia de otros, llegue a un razonable conjunto de creencias acerca de lo que es bueno para sus ciudadanos", y afirma también: "nada excluye la posibilidad de que los gobiernos puedan advertir errores en las concepciones del bien de las personas" (Kymlicka 1990, p. 203).
}

Diánoia, vol. LI, no. 56 (mayo 2006). 
Aceptemos provisionalmente que el argumento anterior ofrece buenas razones para dejar de lado políticas perfeccionistas que impliquen limitaciones coercitivas a la posibilidad de revisar el valor o la corrección de nuestras creencias y actividades. La promoción no coercitiva de concepciones del bien (a través de campañas, publicidad, subsidios, etc.) no parece constituir ni implicar en forma directa limitación alguna para la capacidad de los ciudadanos de revisar y modificar sus creencias o sus formas de vida; de modo que el argumento no permite excluir todo el rango de políticas perfeccionistas que son impugnables a partir de la tesis de la neutralidad.

Las dificultades no terminan aquí. Es posible cuestionar también la idea de que este argumento permite excluir políticas perfeccionistas coercitivas. A la luz de la segunda interpretación de la tesis falibilista enfrentamos dos alternativas. La primera supone extender el paralelismo con la concepción popperiana. En ese caso podremos sostener que, aunque no dispongamos de la capacidad de alcanzar la verificación de nuestras creencias, está a nuestra disposición la de refutar ciertas opiniones. Esta capacidad, como sabemos, es la clave de la posibilidad del progreso dentro del planteamiento de Popper. Si podemos, tras la reflexión crítica, descubrir que ciertos puntos de vista son erróneos, aunque nunca tengamos la certeza de que las creencias más plausibles (más resistentes a la refutación) sean verdaderas, podemos dar sentido a la idea de que se ha producido un progreso en nuestro conocimiento o nuestra comprensión de la materia en cuestión, y resultará razonable reconocer el valor de la libertad para revisar nuestras creencias como medio de promoción de tal progreso. Resultará plausible también la tesis, defendida por Kymlicka, de que somos capaces de realizar juicios objetivos en cuestiones relativas a la buena vida. Sin embargo, surge un inconveniente: ¿qué ganaría el Estado, en términos consecuencialistas, permitiendo que las personas revisen críticamente o vivan de acuerdo con creencias que han sido refutadas, que sabemos que son erróneas? Permitir tal cosa sería contraproducente para el bienestar de las personas, pues maximizaría las probabilidades de que cometan errores. Si el objetivo del Estado es promover la buena vida, como concede Kymlicka a los perfeccionistas, ¿por qué permitirlo?

Eliminar la posibilidad de refutación, como vimos al examinar el argumento de Rivera López, introduce otro tipo de problemas. Si no somos capaces de descartar ninguna creencia acerca de en qué consiste vivir una buena vida por más implausible o absurda que pueda parecer, entonces ¿qué clase de avance podemos hacer en nuestro conocimiento de este tipo de cuestiones?, ¿qué valor podría tener en estas condi- 
ciones revisar libremente nuestras creencias? Si no podemos progresar en nuestro conocimiento acerca de aquello en lo que consiste vivir una buena vida, la libertad para revisar críticamente nuestras creencias pierde su valor.

Un argumento contra las objeciones precedentes consistiría en afirmar que la imposibilidad de refutar con plena certeza ciertas creencias no elimina necesariamente la capacidad de las personas para realizar juicios objetivos. Aun en el caso de las ciencias, la refutación definitiva de teorías resulta una posibilidad más teórica que real. Mientras la verificación de una ley científica es, por razones lógicas y semánticas, teóricamente imposible, la refutación es teóricamente posible pero fácticamente improbable. La derivación, a partir de una hipótesis nomológica de las consecuencias observacionales de las que depende la refutación, normalmente no puede ser llevada a cabo sin apelar a hipótesis auxiliares. En caso de que la comprobación empírica concluya finalmente en la refutación, lo refutado es, en realidad, la conjunción de la supuesta ley científica y las hipótesis auxiliares. Siempre existe la posibilidad de que estas últimas, y no la teoría, contengan los errores responsables de la refutación, de modo que resulta en extremo remota la posibilidad de decretar con certeza la refutación de una teoría científica. Es plausible afirmar que en cuestiones evaluativas, donde las dificultades cognoscitivas parecen ser mucho mayores que en las ciencias, resultará aún más improbable estar en condiciones de considerar definitivamente refutada una creencia particular o un conjunto de creencias. Ahora bien, si la imposibilidad de hacer una refutación definitiva no constituye un obstáculo para la objetividad en el campo científico, ¿por qué razón debería constituirlo en el evaluativo? Quizá las dificultades sean mayores, pero no hay necesidad de suponer, al menos en principio, que son insuperables. Si esto es así, al margen de la imposibilidad de hacer una refutación definitiva, la afirmación de que ciertas concepciones del bien son altamente implausibles mientras otras, por el contrario, aparecen como significativamente sólidas y atractivas, podrían estar basadas en buenas razones y constituir, en definitiva, alguna clase de juicio o de conocimiento objetivo. Supongamos que esta posición es consistente. Ahora bien, si el resultado de nuestros juicios representa alguna clase de conocimiento objetivo o de creencia dotada de respaldo racional, tomarlo como base para nuestras acciones debe ofrecernos alguna garantía ${ }^{34}$ o aumento de probabilidades de éxito. Debe

\footnotetext{
${ }^{34}$ Aun cuando no se trate de garantías absolutas, dado que no estarán basadas en un conocimiento definitivo, sino, digamos, en un conocimiento en sentido débil, siempre sujeto a la posibilidad de error.
} 
darnos alguna clase de garantías (aunque no sean absolutas) de que, actuando con base en él, tendremos más posibilidades o probabilidades de vivir una buena vida que obrando de forma contraria. Creo que éste es el requisito mínimo que podemos exigir a un conjunto de creencias para poder considerarlas, en algún sentido, como una forma de "conocimiento objetivo" o describirlas como "racionalmente justificadas o respaldadas". Admitamos que esta clase de conocimiento objetivo o de creencia racional es posible en cuestiones referentes a la buena vida y que el Estado puede alcanzarlo, como, según vimos, lo reconoce Kymlicka. Si un Estado actúa con base en ese conocimiento, promoviendo una concepción del bien o impidiendo que los ciudadanos la abandonen para realizar actividades juzgadas como carentes de valor, habrá, por lo tanto, más probabilidades de que esas políticas perfeccionistas promuevan el bienestar de los ciudadanos que las ofrecidas por una política que se abstenga de apelar a ese conocimiento disponible y permita acciones contrarias a él, como ocurriría en caso de respetarse la tesis de la neutralidad. Por lo tanto, podemos concluir que desde la perspectiva consecuencialista dentro de la que nos estamos moviendo, tenemos buenas razones para preferir y considerar justificadas ese tipo de políticas perfeccionistas directas.

La misma argumentación podría ser formulada en defensa del argumento de Rivera López, pero, como podrá anticipar el lector, es susceptible de una respuesta semejante a la que acabo de desarrollar. Una vez aceptado el supuesto de que somos capaces de poseer un conocimiento objetivo o creencias racionalmente fundadas en cuestiones relativas a la buena vida, se resuelve, aunque de manera también adversa para el argumento falibilista, el dilema del experimento mental propuesto páginas atrás. Si somos capaces de llegar a concluir con base en "buenas razones" que nuestras creencias actuales son las verdaderas o más probablemente verdaderas, frente al informe de que las abandonaremos en el futuro, la respuesta racional consistirá en considerar que tenemos un interés legítimo en que se nos impida modificarlas, con lo cual la opción elegida será una política perfeccionista.

De modo semejante, puede sostenerse que, aun cuando no podamos tener la certeza absoluta de que las creencias que juzgamos falsas lo sean efectivamente, si ese juicio representa una forma de conocimiento objetivo de alguna clase, una política estatal orientada a promover las creencias contrarias, o a persuadir a los ciudadanos que las profesan que las abandonen, resultará justificada desde el punto de vista consecuencialista. Dicha política tendrá más probabilidad de promover el bienestar de los ciudadanos que una política neutral. Ninguna política 
del Estado, ya sea relativa a la buena vida, a la justicia social, a la economía o a la conservación del medio ambiente, podría contar con una base de justificación más sólida en términos de sus consecuencias previsibles para el bienestar de los ciudadanos; cualquiera de ellas dependerá de creencias sobre lo que promueve o daña dicho bienestar, cuya falsedad no podemos descartar con certeza absoluta. Pero si este hecho no es una razón para suspender todas esas políticas, no lo es tampoco para suspender las políticas perfeccionistas. Nuevamente, podemos afirmar que la tesis falibilista no genera razones para la acción. O se aplica a toda política gubernamental — no sólo a las perfeccionistas- y permite cuestionar la existencia misma del Estado, lo cual parece implausible, o resulta irrelevante.

La conclusión final es que los argumentos falibilistas consecuencialistas son, en forma evidente, incapaces de impugnar las políticas perfeccionistas no coercitivas, y que su aptitud para dar pie a objeciones relevantes contra las políticas coercitivas resulta minada por la inestabilidad o inconsistencia conceptual que entrañan. Necesitan diferenciarse del escepticismo, dado que éste disuelve el sentido mismo de formular el tipo de argumentos morales de orden consecuencialista que pretenden constituir; pero ese mismo paso, a saber, tomar distancia del escepticismo, los vuelve incapaces de explicar en forma convincente las ventajas de la neutralidad estatal, entendida como una forma de perfeccionismo indirecto, con respecto a las políticas perfeccionistas directas. Ello se debe a que una vez reconocida la posibilidad de poseer un conocimiento objetivo o creencias dotadas de respaldo racional acerca de aquello en lo que consiste la buena vida - aun cuando se trate de un conocimiento en sentido débil-y admitido a su vez el supuesto de que la finalidad de las políticas del Estado es promover la buena vida, la apelación a la premisa falibilista no excluye ni refuta la preferibilidad, en una amplia gama de casos y situaciones, de las políticas perfeccionistas directas. Es necesario reconocer que estos argumentos señalan los peligros de dichas políticas y subrayan la importancia de aplicar mecanismos para contrarrestar en lo posible esos peligros, pero no constituyen una adecuada defensa de la tesis liberal de la neutralidad.

\section{BIBLIOGRAFÍA}

Austin, J.L., 1970, Philosophical Papers, Oxford University Press, Londres. Barry, B., 1995, Justice as Impartiality, Oxford University Press, Nueva York.

[Versión en castellano: La justicia como imparcialidad, trad. José Pedro Tosaus Abadía, Paidós, Barcelona/México, 1997.]

Diánoia, vol. LI, no. 56 (mayo 2006). 
De Marneffe, P., 1990, "Liberalism, Liberty, and Neutrality", Philosophy and Public Affairs, vol. 19, no. 3, pp. 253-274.

Habermas, J., 1992, Factizität und Geltung: Beiträge zur Diskurstheorie des Rechs und des demokratischen Rechtsstaats, Suhrkamp, Fráncfort del Meno. [Versión en castellano: Facticidad y validez sobre el derecho y el Estado democrático de derecho en términos de teoría del discurso, introd. y trad. (a partir de la 4a. ed. revisada) Manuel Jiménez Redondo, Trotta, Madrid, 1998.]

Hurka, Th., 1995, "Indirect Perfectionism: Kymlicka on Liberal Neutrality", The Journal of Political Philosophy, vol. 3., no. 1, pp. 36-57.

Kymlicka, W., 1995, Multicultural Citizenship, Oxford University Press, Oxford.

— 1990, Contemporary political Philosophy, Clarendon Press, Oxford.

— 1989a, Liberalism, Community and Culture, Clarendon Press, Oxford.

_ 1989 b, "Liberal Individualism and Liberal Neutrality", Ethics, vol. 99, pp. 883-905.

Mill, J.S., 1975, Three Essays: On liberty, Representative Government, The Subjection of Women, Oxford University Press, Londres.

Rawls, J., 1993 Political Liberalism, Columbia University Press, Nueva York. [Versión en castellano: Liberalismo político, trad. Sergio René Madero Báez, Facultad de Derecho-UNAM/Fondo de Cultura Económica, México, 1995.]

Rivera López, E., 1997, "De la racionalidad a la razonabilidad: ¿es posible una fundamentación epistemológica de una moral política?”, Crítica, vol. 29, no. 86 , pp. 53-81.

Recibido el 13 de junio de 2005; aceptado el 23 de febrero de 2006. 